\title{
Physiotherapy exercises and back pain: a blinded review
}

\author{
B W Koes, L M Bouter, H Beckerman, G J M G van der Heijden, P G Knipschild
}

Abstract

Objective-To determine the quality of randomised controlled trials of excercise therapy for back pain.

Design-Computer aided search of published papers and blinded assessment of the methods of studies.

Subjects -23 randomised controlled trials, of which 16 studied exercise therapy given by physiotherapists to individual patients with back pain. Other conservative treatments could be included.

Main outcome measures-Score for quality of methods (based on four main categories: study population, interventions, measurement of effect, and data presentation and analysis) and main conclusion of author(s) with regard to exercise therapy.

Results-Only four studies scored more than $\mathbf{5 0}$ points (maximum 100), indicating that most were of poor quality. Six studies found that exercise was better than reference treatments and 10 reported it to be no better or worse than the reference treatment. Those reporting positive results tended to have higher methods scores (4/6 positive $v$ //10 negative scored $\geqslant 42$ ).

Conclusions - No conclusion can be drawn about whether exercise therapy is better than other conservative treatments for back pain or whether a specific type of exercise is more effective. Further trials are needed in which greater attention is paid to methods of study.

\section{Introduction}

Epidemiological studies indicate that about $80 \%$ of the population will suffer from back pain during their active lives. ${ }^{12}$ Fortunately, the complaints are usually self limiting, and in about $90 \%$ of patients the complaints disappear within a few months, often with the help of some rest, analgesics, and home exercises. ${ }^{23}$ For patients with chronic back pain there are many therapeutic interventions available, but none seems to be clearly better than the others. ${ }^{23}$

Although exact figures are lacking, physiotherapy is probably the treatment most widely used for back complaints. ${ }^{46}$ Physiotherapists usually give exercise therapy, alone or in combination with other treatments (for example, massage, heat, traction, ultrasound, or short wave diathermy). Despite their widespread use the efficacy of these treatments still remains questionable. ${ }^{2378}$ Rationales for exercise in the management of back pain include relieving compression of the nerve in the intervertebral foramen, shifting nuclear material away from the bulging annulus (in the case of a protruded disc), increasing endorphin concentrations, strengthening weak muscles, decreasing mechanical stress, stabilising hypermobile segments, and improving posture and mobility. ${ }^{910}$ Whether the presumed rationale is valid can only be evaluated in randomised clinical trials. The methods used in such trials of physiotherapy have been shown to vary substantially. ${ }^{8}$ Studies with serious flaws in their methods tend to report biased outcomes. We present a review of randomised controlled trials assessing the efficacy of exercises for back pain.
Methods

We conducted a MEDLINE search of papers published during 1966-90 (keywords: backache, musculoskeletal diseases, joint diseases, spina diseases, physical therapy, evaluation studies, outcome, and process assessment). In addition, a number of relevant journals that are not covered by MEDLINE were screened. Abstracts and unpublished studies were not included. To be included in this review studies had to meet three conditions. Firstly, the physiotherapy regimen should include exercise therapy provided by physiotherapists. Additional physica treatment modalities (for example, ultrasound or shor wave diathermy) were allowed. Studies in which the exercise therapy was given in groups (for example, fitness training, back school programmes) were excluded. Secondly, the subjects in the study must have had back pain at the moment of inclusion. Initially, we were also interested in the efficacy of physiotherapy exercises for neck pain, but only one study was found. ${ }^{11}$ Thirdly, the study must be a randomised clinical trial. This design is generally considered to be the paradigm for intervention studies because of its potential to provide a valid assessment of the efficacy of an intervention. ${ }^{12} 13$

Table I shows the criteria used for assessing the methodological quality of the trials. This list was adapted from Ter Riet $e t a l,{ }^{14}$ and the criteria are based on generally accepted principles of intervention research. ${ }^{12}{ }^{13}$ Studies could earn points in four categories dealing with the study population, interventions, measurement of effect, and data presentation and analysis. The maximum score was 100 points. The papers to be reviewed were first blinded for author(s), journal, and outcome by one of us (BWK). Thereafte the quality of the studies' methods was assessed by two blinded reviewers (HB, GJMGH) independently In a subsequent meeting the reviewers tried to reach consensus on each criterion they disagreed about Where disagreement persisted, a third blinded

TABLE I - Criteria for assessing methods in randomised clinical trials of physiotherapy exercises for back complaints

\begin{tabular}{ll}
\hline Criterion $^{\star}$ & Weighting \\
\hline
\end{tabular}

Study population $(\mathrm{n}=35)$

A Homogeneity

B Comparability of relevant baseline characteristics

Adequate randomization procedure

D Drop outs described for each study group separately

$<20 \%$ loss to follow up $<20 \%$ loss to follow up

$>50$ subjects in the smallest group

$>100$ subjects in the smallest group

Interventions $(\mathbf{n}=25)$ :

$\mathrm{G}$ Interventions included in protocol and described

H Pragmatic study

I Co interventions avoided

Placebo controlled

Measurement of effect $(n=30)$ :

Measurement of effect

$\begin{array}{ll}\mathrm{K} & \text { Patients blinded } \\ \mathrm{L} & \text { Relevant outcome measures }\end{array}$

L Belevant outcome measures

$\mathrm{N}$ Adequate follow up period

Data presentation and analysis $(n=10)$ :

$\mathrm{O}$ Intention to treat analysis

P Frequencies of most important outcomes presented for each treatment group

$\star$ Further details given in appendix. 
reviewer (LMB) made the final decision. The assessments resulted in a hierarchical list in which higher scores indicate studies that used better methods.

A study was labelled "positive" if its author(s) concluded that one of the exercise modalities was more effective than the reference treatment. Generally, this meant that the differences were significant. A study was considered "negative" when the author(s) reported no difference between the study treatments or showed better results with the reference treatment.

\section{Results}

A total of 23 studies were considered for inclusion, seven of which were rejected. In three of these all study groups received the same exercises thus making it impossible to assess the effects of the exercise regimen separately, ${ }^{15-17}$ two publications described different aspects of the same trial in which the exercises were given in groups, ${ }^{18}{ }^{19}$ and in one trial only a few patients in both study groups performed exercises. ${ }^{20}$ Two publications turned out to deal with the same study. After assessing both publications the one with the lowest score was rejected. ${ }^{21}$ Sixteen randomised clinical trials met the conditions for inclusion. Table II presents all trials in a hierarchial order according to their methods score.

Only four trials scored 50 or more points, indicating that the methods of most studies were poor. The main shortcomings were: lack of description of drop outs, considerable loss to follow up, small samples sizes, use of cointerventions with exercise therapy, no placebo control group, lack of blinding of patients, and no intention to treat analysis.

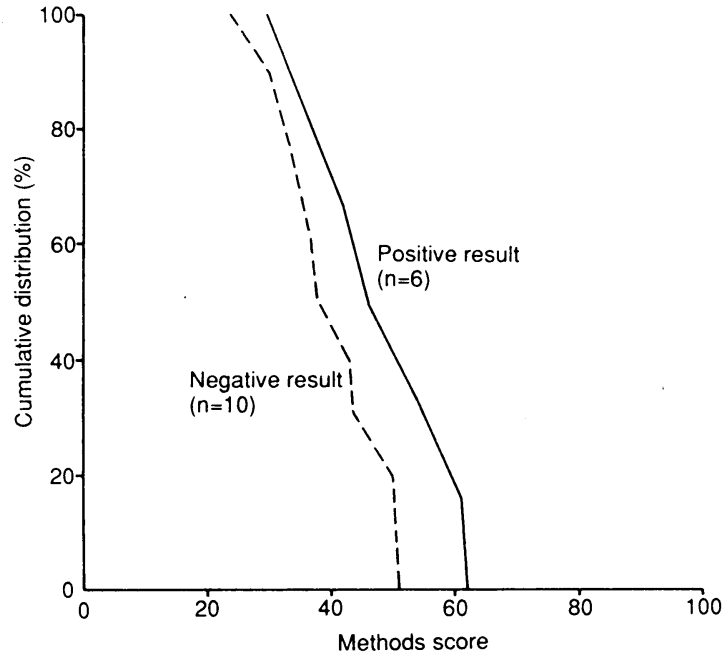

Relation between methods score of trials and their results. (Positive result shows exercise is better than reference treatment, negative result shows exercise is no better or worse than reference treatment)

The figure presents the relation between the methods $\mathrm{N}$ score and the overall conclusion (positive or negative) of the studies. Included are six positive studies and 10 을 negative studies. Only four $(40 \%)$ of the 10 negative studies scored 43 points or more, while four $(67 \%)$ of $v$ the six positive studies scored 42 points or more. In $N$ general the positive studies seemed to have higher methods scores.

It is difficult to draw conclusions about the efficacy of exercise therapy, because some studies compare exercise therapy with another conservative treatment

TABLE II-Randomised trials of the efficacy of exercise therapy for back pain in order of methods score

\begin{tabular}{|c|c|c|c|c|c|c|c|c|c|c|c|c|c|c|c|c|c|c|c|}
\hline \multirow[b]{2}{*}{ Author } & \multicolumn{16}{|c|}{ Score for methods criteria } & \multirow[b]{2}{*}{$\begin{array}{c}\text { Total score } \\
(100)\end{array}$} & \multirow[b]{2}{*}{ Indication $\dagger$} & \multirow[b]{2}{*}{ Conclusion $\ddagger$} \\
\hline & $\begin{array}{c}\text { A } \\
(2)\end{array}$ & $\begin{array}{l}\text { B } \\
(5)\end{array}$ & $\begin{array}{c}\mathrm{C} \\
(4)\end{array}$ & $\begin{array}{c}\mathrm{D} \\
(3)\end{array}$ & $\begin{array}{c}E \\
(4)\end{array}$ & $\begin{array}{c}\mathbf{F} \\
(17)\end{array}$ & $\begin{array}{c}\mathrm{G} \\
(10)\end{array}$ & $\begin{array}{l}\mathbf{H} \\
(5)\end{array}$ & $\begin{array}{c}\text { I } \\
(5)\end{array}$ & $\underset{(5)}{J}$ & $\begin{array}{c}\mathbf{K} \\
(5)\end{array}$ & $\begin{array}{c}\mathrm{L} \\
(10)\end{array}$ & $\begin{array}{c}M \\
(10)\end{array}$ & $\begin{array}{l}N \\
(5)\end{array}$ & $\begin{array}{c}\mathrm{O} \\
(5)\end{array}$ & $\begin{array}{l}\mathbf{P} \\
(5)\end{array}$ & & & \\
\hline Deyo et $a l^{22}$ & 1 & 3 & 4 & 3 & 2 & 8 & 10 & 5 & & & & 10 & 2 & 3 & 5 & 5 & 61 & Chronic low back pain & Positive \\
\hline Manniche et $a l^{23}$ & 2 & 1 & 4 & 3 & 2 & & 10 & 5 & & & & 10 & 2 & 5 & 5 & 5 & 54 & Chronic low back pain & Positive \\
\hline Evans et al $l^{4}$ & 2 & 5 & & & & 8 & 10 & 5 & & & & 10 & 2 & 5 & & 5 & 50 & Acute low back pain & Negative \\
\hline Coxhead et al ${ }^{\text {s }}$ & 1 & 2 & & & 4 & 17 & & 5 & & & & 6 & & 5 & 5 & 5 & 50 & Sciatic symptoms & Negative \\
\hline Lidström, Zachrisson ${ }^{4}$ & 1 & 2 & & 3 & 4 & & 10 & 5 & & & & 6 & 2 & 3 & 5 & 5 & 46 & Chronic low back pain and sciatica & Positive \\
\hline Zylbergold, Piper & 1 & 2 & & 3 & 4 & & 10 & 5 & & & & 6 & & 3 & 5 & 5 & 44 & Lumbar disc disease & Negative \\
\hline Waterworth, Hunter ${ }^{26}$ & 2 & 5 & & 3 & 4 & & 5 & 5 & 5 & & & 6 & & 3 & 5 & & 43 & Acute low back pain & Negative \\
\hline Stankovic, Johnell ${ }^{27}$ & 1 & 3 & 4 & 3 & 4 & & 10 & 5 & & & & 2 & & 5 & 5 & & 42 & Acute low back pain & Positive \\
\hline Nwuga ${ }^{28}$ & 2 & 4 & 2 & & & & 10 & 5 & & & 3 & 2 & 2 & 3 & & 5 & 38 & Prolapsed disc & Negative \\
\hline Farrell, Twomey ${ }^{\circ}$ & 2 & 5 & & & 2 & & 10 & 5 & & & & 8 & 2 & 3 & & & 37 & Acute low back pain & Negative \\
\hline Kendall, Jenkins ${ }^{30}$ & 1 & & 2 & & 2 & & 10 & 5 & & & & 6 & 2 & 3 & & 5 & 36 & Chronic back pain & Positive \\
\hline Martin et $a l^{\circ}$ & 2 & & 2 & & & & 10 & 5 & & 5 & & 6 & 2 & 3 & & & 35 & Chronic low back pain & Negative \\
\hline Davies $e t a l^{\prime \prime}$ & 2 & 3 & & & 4 & & & 5 & & & 3 & 6 & 2 & 3 & & 5 & 33 & Sub (acute) low back pain & Negative \\
\hline Buswell $^{32}$ & & 1 & & & & & 10 & 5 & & & & 4 & & 5 & 5 & & 30 & Chronic low back pain & Negative \\
\hline Nwuga, Nwuga ${ }^{33}$ & 2 & 2 & 2 & & & & & 5 & & & 3 & 4 & 2 & 3 & & 5 & 28 & Prolapsed disc & Positive \\
\hline White ${ }^{34}$ & 1 & & & & & 8 & & 5 & 5 & & & 2 & & 3 & & & 24 & Chronic low back pain & Negative \\
\hline
\end{tabular}

*See appendix for details of criteria

The labels chronic and acute are according to the authors of the study. Classification might therefore vary between the studies.

†Conclusion of the authors(s) of the study. Positive conclusion $=$ exercise better than control treatment; negative conclusions=exercise worse than or equally effective as control treatment.

TABLE III -Details of trials comparing exercise therapy with other conservative treatments

\begin{tabular}{|c|c|c|c|c|c|c|}
\hline Author & & Exercise regimen (No of patients) & & Reference treatment (No of patients) & Methods score & Results $^{\star}$ \\
\hline Lidström, Zachrisson ${ }^{4}$ & $\begin{array}{l}\text { (i) } \\
\text { (ii) }\end{array}$ & $\begin{array}{l}\text { Isometric strengthening and pelvic } \\
\text { traction (20) } \\
\text { Mobilising/strengthening } \\
\text { hot packs and massage ( } 21)\end{array}$ & (iii) & Hot packs and rest $(21)$ & 46 & $\begin{array}{l}\text { No of patients with noticeable improvement after } 4 \text { weeks: } \\
\text { (i) } 17 \text {, (ii) } 9 \text {, (iii) } 12 \\
\text { Patients in group (i) significantly better than those in other } \\
\text { groups }\end{array}$ \\
\hline Zylbergold, Pipers & $\begin{array}{l}\text { (i) } \\
\text { (ii) }\end{array}$ & $\begin{array}{l}\text { Flexion and heat }(10) \\
\text { Home care instructions }(10)\end{array}$ & (iii) & Manual therapy and heat $(8)$ & 44 & $\begin{array}{l}\text { Mean (SD) change in pain intensity on } 5 \text { point scale after } 1 \\
\text { month: (i) }-1 \cdot 0(0.85),(\text { ii })-1 \cdot 5(0 \cdot 10) \text {, (iii) }-0.6 \\
(0.82) \text {. No significant difference in pain or mobility }\end{array}$ \\
\hline Waterworth, Hunter, ${ }^{26}$ & (i) & $\begin{array}{l}\text { Flexion and extension, short wave } \\
\text { diathermy and ultrasound ( } 34)\end{array}$ & $\begin{array}{l}\text { (ii) } \\
\text { (iii) }\end{array}$ & $\begin{array}{l}\text { Non-steroidal anti-inflammatory } \\
\text { drugs ( } 36 \text { ) } \\
\text { Manipulation (38) }\end{array}$ & 43 & $\begin{array}{l}\text { Mean change in pain intensity on } 4 \text { point scale after } 4 \text { and } \\
12 \text { days: (i) }-0 \cdot 9,-1 \cdot 6 \text {; (ii) }-0 \cdot 9,-1 \cdot 7 \text {; (iii) }-1 \cdot 1 \text {, } \\
-1 \cdot 7 \text {. No significant difference in pain and mobility }\end{array}$ \\
\hline Stankovic, Johnell ${ }^{27}$ & (i) & McKenzie (extension) (50) & (ii) & Mini back school (50) & 42 & $\begin{array}{l}\text { Less pain in exercise group with reference at } 3 \text { weeks and a } \\
\text { year (no data) }\end{array}$ \\
\hline Nwuga $^{28}$ & (i) & $\begin{array}{l}\text { Isometric flexion back and abdominal } \\
\text { muscles and short wave diathermy }(25)\end{array}$ & (ii) & Manipulation (26) & 38 & $\begin{array}{l}\text { Improvement in spinal flexion and straight leg raising: } \\
\text { (i) } 13^{\circ}, 4^{\circ} \text {; (ii) } 434^{\circ}, 39^{\circ} \text {. Manipulation significantly better } \\
\text { than exercise }\end{array}$ \\
\hline Farrell, Twomey ${ }^{29}$ & (i) & $\begin{array}{l}\text { Isometric flexion abdominal muscles and } \\
\text { microwave diathermy (24) }\end{array}$ & (ii) & Manipulation and mobilisation (24) & 37 & $\begin{array}{l}\text { Manipulation group were symptom free in significantly } \\
\text { less days (data in graphs) }\end{array}$ \\
\hline Davies et $a l^{31}$ & $\begin{array}{l}\text { (i) } \\
\text { (ii) }\end{array}$ & $\begin{array}{l}\text { Extension and short wave diathermy (14) } \\
\text { Isometric flexion and short wave. } \\
\text { diathermy (14) }\end{array}$ & (iii) & Short wave diathermy (15) & 33 & $\begin{array}{l}\text { No of patients showing improvement after } 2 \text { and } 4 \text { weeks: } \\
\text { (i) } 11,13 \text {; (ii) } 7,12 \text {; (iii) } 8,10 \text {. No significant difference }\end{array}$ \\
\hline
\end{tabular}




\begin{tabular}{|c|c|c|c|c|c|c|}
\hline Author & & Exercise regimen (No of patients) & & eference treatment (No of patients) & Methods score & Results* \\
\hline Deyo et al ${ }^{2}$ & (i) & $\begin{array}{l}\text { Stretching exercises and transcutaneous } \\
\text { electrial nerve stimulation }(34) \\
\text { Stretching exercises and sham } \\
\text { transcutaneous electrical nerve } \\
\text { stimulation (29) }\end{array}$ & (iii) & $\begin{array}{l}\text { Transcutaneous electrial nerve } \\
\text { stimulation }(31) \\
\text { Sham transcutaneous electrical nerve } \\
\text { stimulation }(31)\end{array}$ & 61 & $\begin{array}{l}\text { Mean improvement on visual analogue scale for pain and } \\
\text { activity }(0-100 \%) \text { after } 4 \text { and } 12 \text { weeks: (exercises } i \text { and ii) } \\
52 \%, 48 \% ;(\text { reference iii and iv) }), 37 \%, 41 \% \text {. Exercise } \\
\text { significantly better }\end{array}$ \\
\hline Evans et al $l^{2+}$ & (i) & $\begin{array}{l}\text { Isometric flexion, education, and bedrest } \\
(65) \\
\text { Isometric flexion and education (62) }\end{array}$ & (iii) & $\begin{array}{l}\text { Bedrest }(60) \\
\text { No intervention }(65)\end{array}$ & 50 & $\begin{array}{l}\text { No of patient reporting no pain after } 6 \text { and } 12 \text { weeks: (i) } 34 \text {, } \\
47 \text { (ii) } 33,46 \text { (iii) } 36,44 \text { (iv) } 33,43 \\
\text { No significant difference in pain, mobility or daily activities }\end{array}$ \\
\hline Coxhead et al ${ }^{\alpha}$ & (i) & $\begin{array}{l}\text { Exercises using all ranges of motion and } \\
\text { muscle groups given alone or with } \\
\text { traction, manipulation, or corset (150) }\end{array}$ & (ii) & $\begin{array}{l}\text { No intervention, traction, } \\
\text { manipulation, or corset (142) }\end{array}$ & 50 & $\begin{array}{l}\text { No of patients reporting to feel better compared with } \\
\text { baseline after } 4 \text { weeks and } 4 \text { months: exercise (i) } 120,85 \text {; } \\
\text { reference (ii) } 107,96 \text {. No significant difference }\end{array}$ \\
\hline Martin $e t a l^{p}$ & (i) & $\begin{array}{l}\text { Mobilising abdominal and back muscles } \\
\text { (12) } \\
\text { Isometric abdominal and pelvic floor } \\
\text { muscles (12) }\end{array}$ & (iii) & $\begin{array}{l}\text { Detuned ultrasound and detuned } \\
\text { short wave diathermy (12) }\end{array}$ & 35 & $\begin{array}{l}\text { Change in pain intensity ( } 5 \text { point scale) after } 5 \text { weeks } \\
\text { (i) decrease, (ii) increase (iii) decrease. No significant } \\
\text { difference in this or other physiological and clinical } \\
\text { measures }\end{array}$ \\
\hline
\end{tabular}

${ }^{\star}$ Results of the most important outcome measure according to the author(s) of the study. When not explicitly stated presentation of pain or a global measure of improvement.

p Values $<0.05$ were taken as significant.

TABLE $\mathrm{V}$-Details of trials comparing different exercise regimens

\begin{tabular}{|c|c|c|c|c|}
\hline Author & & Exercise regimen (No of patients) & Methods score & Results* \\
\hline Manniche et $\mathrm{l}^{33}$ & $\begin{array}{l}\text { (i) } \\
\text { (ii) } \\
\text { (iii) }\end{array}$ & $\begin{array}{l}\text { Intensive back extensor (27) } \\
\text { Mild isometric and massage and hot } \\
\text { compress ( } 32 \text { ) } \\
\text { Mild back extensor ( } 31 \text { ) }\end{array}$ & 54 & $\begin{array}{l}\text { Improvement (median and } 10 \text { th/90th centile) in } \\
\text { combined pain, disability, physical impairment } \\
\text { index }(0-100 \text { points) after } 3 \text { and } 9 \text { months: (i) } 14 \cdot 7 \\
(-3 \cdot 2 / 29 \cdot 4), 15 \cdot 0(-8 \cdot 4 / 31 \cdot 4) ;(\text { ii) } 2 \cdot 0(-11 \cdot 7 / \\
19 \cdot 5), 5 \cdot 5(-12 \cdot 8 / 19 \cdot 5) ;(\text { iii) }) 5 \cdot 7(-4 \cdot 4 / 23 \cdot 7), 7 \cdot 0 \\
(-11 \cdot 0 / 21 \cdot 5) \text {. Intensive back extensor exercises (i) } \\
\text { significantly better }\end{array}$ \\
\hline Lidström, Zachrisson ${ }^{4}$ & $\begin{array}{l}\text { (i) } \\
\text { (ii) }\end{array}$ & $\begin{array}{l}\text { Isometric flexion and pelvic traction }(20) \\
\text { Mobilising/strengthening, hot packs and } \\
\text { massage (21) }\end{array}$ & 46 & $\begin{array}{l}\text { No of patients with noticeable improvement after } 4 \\
\text { weeks: (i) } 17 \text {, (ii) } 9 \text {. Isometric flexion (i) } \\
\text { significantly better than (ii), but not significant }\end{array}$ \\
\hline Kendall, Jenkins ${ }^{30}$ & $\begin{array}{l}\text { (i) } \\
\text { (ii) } \\
\text { (iii) }\end{array}$ & $\begin{array}{l}\text { Isometric flexion (14) } \\
\text { Mobilising (14) } \\
\text { Extension (14) }\end{array}$ & 36 & $\begin{array}{l}\text { No of patients symptoms free or improved after } 1 \text { and } \\
3 \text { months: (i) } 13,11 \text {; (ii) } 11,8 \text {; (iii) } 7,6 \text {. Isometric } \\
\text { flexion significantly better }\end{array}$ \\
\hline Martin $e t a l^{b}$ & (i) & $\begin{array}{l}\text { Isometric flexion abdominal and pelvic floor } \\
\text { muscles (12) } \\
\text { Mobilising abdominal and back muscles (12) }\end{array}$ & 35 & $\begin{array}{l}\text { Change in pain rating ( } 5 \text { point scale) after } 5 \text { weeks: } \\
\text { (no exact figures given) (i) deterioration (ii) } \\
\text { improvement. No differences in physiological and } \\
\text { clinical measures }\end{array}$ \\
\hline Davies $e t a l^{\prime \prime}$ & $\begin{array}{l}\text { (i) } \\
\text { (ii) }\end{array}$ & $\begin{array}{l}\text { Isometric flexion and short wave diathermy } \\
\text { (14) } \\
\text { Extension and short wave diathermy (14) }\end{array}$ & 33 & $\begin{array}{l}\text { No of patients improved after } 2 \text { and } 4 \text { weeks: (i) } 7,12 \text {; } \\
\text { (ii) } 11,13 \text {. No significant difference }\end{array}$ \\
\hline Buswell $^{32}$ & $\begin{array}{l}\text { (i) } \\
\text { (ii) }\end{array}$ & $\begin{array}{l}\text { Flexion programme }(25) \\
\text { Extension programme }(25)\end{array}$ & 30 & $\begin{array}{l}\text { Similar improvement in pain and function after } \\
\text { treatment for both groups (duration and exact } \\
\text { figures not given) }\end{array}$ \\
\hline Nwuga, Nwuga ${ }^{33}$ & $\begin{array}{l}\text { (i) } \\
\text { (ii) }\end{array}$ & $\begin{array}{l}\text { McKenzie (extension) (31) } \\
\text { Williams (flexion) (31) }\end{array}$ & 28 & $\begin{array}{l}\text { Change in } 10 \text { points pain rating after } 6 \text { weeks: (i) } \\
-5 \cdot 3 \text {, (ii) }-2 \cdot 7 \text {. McKenzie extension significantly } \\
\text { better }\end{array}$ \\
\hline White ${ }^{34}$ & $\begin{array}{l}\text { (i) } \\
\text { (ii) }\end{array}$ & $\begin{array}{l}\text { Mild static trunk and short wave diathermy (76) } \\
\text { Vigorous flexion and extension (72) }\end{array}$ & 24 & $\begin{array}{l}\text { Proportion of patients showing improvement after } \\
\text { treatment (maximum } 7 \text { weeks): (i) } 38 \% \text {, (ii) } 35 \% \text {. } \\
\text { No significant difference }\end{array}$ \\
\hline
\end{tabular}

$\star$ Results of the most important outcome measure according to the author(s) of the study. When not explicitly stated presentation of pain or a global measure of improvement.

p Values $<0.05$ were taken as significant.

or with a placebo therapy, or both, whereas other studies compare different types of exercise. Tables III$\mathrm{V}$ give more specific information on the interventions and the study results.

Table III shows the seven trials that contrasted exercise therapy with other conservative treatments. Two studies found that exercise therapy was better than hot packs and rest, ${ }^{4}$ or mini back school (that isone session of 45 minutes with instructions and education). ${ }^{27}$ In the last study the difference between the two groups was still present one year after randomisation. The five other studies indicated that exercise therapy was not better than manual therapy or home care instructions, ${ }^{5}$ non-steroidal anti-inflammatory drugs, ${ }^{26}$ manipulation, ${ }^{28}$ manipulation and mobilisation, ${ }^{29}$ or short wave diathermy. ${ }^{31}$ These studies included patients with either acute or chronic back pain. However, three negative studies had a low methods score ( $<40$ points).

Table IV gives details of four trials that contrasted exercise therapy with no exercise therapy or placebo therapy. The studies that compared with no exercise therapy used factorial designs ${ }^{22} 2425$; the other comparisons included in the factorial design will not be discussed. The study with the highest methodological score $^{22}$ showed that exercise therapy was better than no exercise therapy for chronic low back pain. After three months follow up the benefit had disappeared. Two other studies with high methods scores found no positive effect for patients with acute low back pain ${ }^{24}$ and patients with sciatic symptoms. ${ }^{25}$ The only study comparing exercise therapy with placebo therapy (detuned ultrasound and detuned short wave diathermy) indicated no differences in effect. ${ }^{5}$

Table $\mathrm{V}$ shows the eight trials which compared different types of exercise therapy. The comparisons were mainly between isometric flexion exercises and extension exercises. Four studies reported no differences between the exercise regimens, but these had major flaws in the design ( $\leqslant 35$ points). ${ }^{613234}$ In four other studies the results favoured one type of $N$ exercise therapy over other types. ${ }^{423} 3033$ In the study $\frac{D}{O}$ with the highest score $\mathrm{e}^{23}$ the results favoured an exercise scheme of three months intensive dynamic back $N$ extensor exercises over a similar treatment at one fifth $\underset{\omega}{N}$ of the exercise intensity and mild isometric training, massage, and heat for patients with chronic low back 6 pain. One other study found on an extension programme to be better than a flexion programme, ${ }^{33}$ but two studies suggested that a flexion programme was better. Lidstrom and Zachrisson reported that isometric flexion exercises in combination with pelvic traction were more effective than mobilising and isotonic strengthening exercises in combination with massage and heat, ${ }^{4}$ and Kendall and Jenkins showed that flexion was more effective than both mobilising exercises and extension exercises. ${ }^{30}$

\section{Discussion}

The 16 trials included in our review can be considered to be the best studies evaluating the efficacy of 
physiotherapy exercises for back pain. Because of their use of control treatments and random allocation of the patients their potential to supply valid answers on this topic is much larger than that of uncontrolled or nonrandomised studies. Nevertheless, we have found that most randomised clinical trials investigating the efficacy of physiotherapy exercises for back pain have major flaws in their methods. Our screening suggests that in the future more attention should be given to the size of the study populations, prevention of loss to follow up (including an adequate description of the patients lost to follow up), comparison with placebo therapy (to control for placebo effects and to avoid bias of effect measurements), and adequate data presentation and statistical analysis.

The reviewers who assessed the trials were blind to the outcome of the studies to prevent reviewer bias. This method has been described by Chalmers $e t a l$ and used to assess the quality of trials on other topics. ${ }^{35} 36$ The criteria chosen for assessing the methods of the studies were not intended to be exhaustive. By using these criteria, however, we believed (before as well as after assessment of the trials) that we could distinguish good studies from bad ones. We chose not to pool the results of the available trials, mainly because we dislike pooling data from studies of high and low methodological quality. The trials that reported negative results of exercises more often had relatively low methods scores. We did not pool the results of the trials with higher methods scores because we thought that the patient characteristics and treatments used in these trials were not similar enough to permit pooling.

The weights that are given to the criteria listed in table 1 have been chosen arbitrarily. For example, we gave sample size a large weight (17 points). The first argument for this was our concern for prognostic comparability at baseline. Because there is only limited knowledge of the aetiology in most cases of back pain and neck pain a major problem is to obtain a homogeneous study population. With increasing numbers of participants one can be more confident that the randomisation procedure will succeed in dividing the known and unknown prognostic factors equally over the study groups. We also thought that publication bias would be less likely with large sample sizes. The effort and costs entailed increase the probability that the trial will be submitted and accepted for publication. ${ }^{37}$ The description of an adequate randomisation procedure was given low weight (four points) as all the studies included were randomised clinical trials and thus satisfied our demand of random allocation of the participants. Studies could, however, earn points with a proper description of an adequate randomisation procedure. Generally the weights were based on our assessment of the relative importance of each criterion. Readers may wish to choose different weights for specific criterion and calculate their own scores.

We conclude that the quality of intervention research on physiotherapy exercises is disappointingly low. Despite its frequent application exercise therapy has not been shown to be more efficacious than other conservative treatment modalities, nor has it been shown to be ineffective. There is little evidence in favour of a specific exercise regimen. Further trials are clearly needed in which much more attention is given to the methods of the studies.

\section{Appendix}

Scoring for criteria listed in table I. Each criterion must be applied independently of the other criteria.

A Description of inclusion and exclusion criteria (1 point). Restriction to a homogeneous study population (1 point).

B Comparability for duration of complaints, value of outcome measures, age, recurrences, and radiating complaints ( 1 point each)

C Randomisation procedure described (2 points). Randomisation procedure which excludes bias (2 points).

D Information about which group subjects dropped out from with reason for withdrawal (3 points).

E Loss to follow up: all randomised patients minus the number of patients still in study at main point of assessing the main outcome measure (according to the author(s)), divided by all randomised patients multiplied by 100 .

F Size of smallest group immediately after randomisation.

G Physiotherapy treatment explicitly described (5 points). All reference treatments explicitly described (5 points).

$\mathrm{H}$ Comparison with other treatments.

I Other medical interventions avoided in the design of the study (except analgesics or use at home of heat, rest, or a routine exercise scheme).

J Comparion with placebo therapy.

K Placebo controlled study: attempted blinding (3 points), blinding evaluated and fully successful ( 2 points).

Pragmatic study: patients fully naive ( 3 points), or time restriction (no physiotherapy exercises in at least one year) (2 points), naiveness evaluated and fully successful (2 points).

L Outcome measures assessed and reported: pain, global measure of improvement, functional status (activities of daily living), spinal mobility, use of medication and medical services ( 2 points each).

M Each blinded measurement mentioned under criterion $N$ L earns 2 points.

$\mathrm{N}$ Outcome measures assessed during or just after treat- $N$ ment ( 3 points). Outcome measures assessed after six months or longer ( 2 points).

O Intention to treat analysis. When loss to follow up is less $\overparen{D}$ than $10 \%$ analysis of data is on all randomised patients $\vec{\theta}$ for main outcome measures and at the most important 6 times of measurement minus missing values (irrespective : of non-compliance and cointerventions). When loss to follow up $>10 \%$ analysis on intention to treat basis as well as a worst case analysis that accounts for missing values.

$P \quad$ Frequency of main outcome measures at the most $\frac{D}{\mathbb{D}}$ important times of measurement. In the case of (semi) continuous variables presentation of the mean or median with a standard error or centiles.

1 Kelsey JL, White AA. Epidemiology and impact of low back pain. Spine $1980 ; 5: 133-42$

2 Frymoyer JW. Back pain and sciatica. N Engl $\mathcal{F}$ Med 1988;318:291-300.

Spizzer WO, assessment and management of activity-related spinal disorders. Spine 1987:12 (suppl 7): 1-59.

4 Lidström A, Zachrisson M. Physical therapy on low back pain and sciatica. Scand $\mathcal{A}$ Rehabil Med 1970;2:37-42.

5 Zylbergold RS, Piper MC. Lumbar disc disease: comparative analysis of physical therapy treatments. Arch Phys Med Rehabil 1981;62:176-9.

6 Martin PR, Rose MJ, Nichols PJR, Russell PL, Hughes JG. Physiotherapy exercises for low back pain: process and clinical outcome. Int Rehabil Med $O$ 1980;8:34-8.

7 Nachemson A. A critical look at the treatment for low back pain. Scand $f \frac{D}{O}$ Rehabil Med 1979;11:143-7.

8 Deyo RA. Conservative therapy for low back pain. FAMA 1983;250:1057-62. N

9 Jackson CP, Brown MD. Is there a role for exercise in the treatment of patients with low back pain? Clin Orthop 1983;179:39-45.

10 Jackson CP, Brown MD. Analysis of current approaches and a practical guide $\sigma$ to prescription of exercise. Clin Orthop 1983;179:46-54

11 Goldie I, Landquist A. Evaluation of the effects of different forms of 0 physiotherapy in cervical pain. Scand $f$ Rehabil Med 1970;2:117-21.

12 Meinert CL. Clinical trials: design, conduct and analysis. New York: Oxford $\mathbb{D}$ University Press, 1986

13 Feinstein AR. Clinical epidemiology: the architecture of clinical research. T Philadelphia: WB Saunders, 1985

14 Ter Riet G, Kleijnen J, Knipschild P. Acupuncture and chronic pain: a criteria-based meta-analysis. I Clin Epidemiol 1990;43:1191-9.

15 Macdonald RS, Bell CMJ. An open controlled assessment of osteopathic manipulation in non-specific low-back pain. Spine 1990;15:364-70.

16 Klaber-Moffett JA, Chase SM, Portek I, Ennis JR. A controlled prospective study to evaluate the effectiveness of a back school in the relief of chronic low back pain. Spine 1986;11:120-2.

17 Landen BR. Heat or cold in the relief of low back pain. Phys Ther 1987;47:1126-8.

18 Harkapa K, Jarvikoski A, Mellin G, Hurri H. A controlled study on the outcome of inpatient and outpatient treatment of low back pain. l. Pain, disability, compliant and disability, complin $1989 \cdot 21 \cdot 81-9$.

19 Mellin G, Hurri H, Harkaapa K, Jarvikoski A. A controlled study on the outcome of inpatient and outpatient treatment of low back pain. 2 . Effects on physical measurements three months after treatment. Scand $\mathcal{Y}$ Rehabil Med 1989;21:91-5. 
20 Meade TW, Dyer S, Browne W, Townsend J, Frank OA. Low back pain of mechanical origin: randomised comparison of chiropractic and hospital outpatient treatment. BMY 1990;300:1431-6.

21 Gilbert JR, Taylor DW, Hildebrand A, Evans C. Clinical trial of common treatments for low back pain in family practice. BMf 1985;291:791 4 .

2 Deyo RA, Walsh NE, Martin DC Schoenfeld IS, Ramamurthy S. A con RA Walled controlled trial of transcutaneous electrical nerve stimulation (TENS) a

23 Manniche C, Hesselsoe G, Bentzen L. Christensen I, Lundberg E. Clinical trial of intensive muscle training for chronic low back pain. Lance 1988;ii: $1473-6$

24 Evans C, Gilbert JR, Taylor DW, Hildebrand A. A randomized controlled trial of flexion exercises, education, and bed rest for patients with acute low back pain. Phvsiotherapy Canada 1987;39:96-101.

25 Coxhead CE, Inskip H, Meade TW, North WRS, Troup JDG. Multicentre trial of physiotherapy in the management of sciatic symptoms. Lancet $1981 ;$ i: $1065-8$.

26 Waterworth RF, Hunter IA. An open study of diflunisal, conservative and manipulative therapy in the management of acute mechanical low back pain. $N Z$ Med f 1985:95:372-5.

27 Stankovic $\mathrm{R}$, Johnell $\mathrm{O}$. Conservative treatment of acute low back pain: a prospective randomized trial. Spine 1990;15:120-3.

28 Nwuga VCB. Relative therapeutic efficacy of vertebral manipulation and
1982;61:273-8.

Tarrell JP, Twomey LT Acute low back pain: compari treatment approaches. Med f A ust 1982;1:160-4.

Kendall PH, Jenkins JM. Exercises for backache: a double-blind controlled trial. Physiotherapy 1968;54:154-7.

31 Davies JR, Gibson T, Tester $\mathrm{L}$. The value of exercises in the treatment of low back pain. Rheumatology and Rehabilitation 1979;18:243-7.

32 Buswell J. Low back pain: a comparison of two treatment programmes. New Zealand fournal of Physiotherapy 1982:10:13-7.

33 Nwuga G, Nwuga V. Relative therapeutic efficacy of the Williams and McKenzie protocols in back pain management. Physiotherapy Practice 1985;1:99-105

34 White AWM. Low back pain in men receiving workmen's compensation. Can Med Assoc f 1966;95:50-6

35 Chalmers TC, Smith H, Blackburn B, et al. A method for assessing the quality of a randomized control trial. Controlled Clin Trials 1981;2:31-49.

36 Tysen J, Furzan J, Reisch J, et al. An evaluation of the quality of therapeutic trials in perinatal medicine. $\mathcal{F}$ Pediatr 1983;102:10-3.

37 Kleijnen J, Knipschild P, Ter Riet G. Clinical trials of homoeopathy. BMF $1991 ; 302: 316-23$.

(Accepted 25 April 1991$)$

\title{
Complications of pregnancy and delivery in relation to psychosis in adult life: data from the British perinatal mortality survey sample
}

\author{
D John Done, Eve C Johnstone, Christopher D Frith, Jean Golding, Peter M Shepherd, \\ Timothy J Crow
}

\section{Abstract}

Objective-To evaluate whether events occurring at or around the time of birth contribute to the onset of psychotic illness in adult life.

Design-Pregnancy and birth complications as possible causes of adult mental illness were studied in the population sample of the British perinatal mortality survey. Subsequent psychiatric admissions were independently identified through the Mental Health Enquiry and records of regional and special health authorities. Logistic regression was used to compare data on perinatal deaths with those on survivors to determine factors independently associated with perinatal death, and this equation was then used to calculate the risk of perinatal death for each survivor.

Subjects -16980 people born in a single week in 1958 (the British perinatal mortality survey sample), including 252 patients admitted to psychiatric care; case notes of 235 patients were supplied.

Main outcome measures and results-Patients

Division of Psychiatry, Clinical Research Centre Watford Road, Harrow, Middlesex HA1 3UJ

D John Done, PHD, senior research officer

Eve C Johnstone, FRCPSYCH, consultant psychiatrist

Christopher D Frith, PHD, senior scientist

Timothy J Crow, FRCPSYCH, head of division

Institute of Child Health, Royal Hospital for Sick Children, Bristol BS2 8B]

Jean Golding, PHD, reader in child health

Social Statistics Research Unit, City University, London EC1V OBH

Peter M Shepherd, BA, senior research fellow

Correspondence to:

Dr Done. have been assessed, of $2-3 \% .^{1-3}$ The role of genetic factors has been established by twin ${ }^{4-6}$ and adoption studies. ${ }^{78}$ It is often assumed there are also environ- $\mathcal{C}$ mental contributions, but their nature is obscure.

One suggestion is that brain damage occurring at or around the time of birth in some way contributes to the later onset of psychosis. ${ }^{9-11}$ The time interval (on 6 average over 20 years) means that there are substantial. practical difficulties in examining an association between perinatal trauma and the later development of psychosis. There have been two types of study: the first (retrospective) has identified a sample of schizophrenic patients and obtained information about their birth $\stackrel{\varnothing}{\varnothing}$ histories; the second (high risk) studied the confine- $\overrightarrow{\overrightarrow{0}}$ ments of mothers with schizophrenia, whose children are at high risk of going on to develop schizophrenia.

Retrospective studies (reviewed in table I) ${ }^{9.20}$ may include carefully selected and documented schizophrenic patients, but it is often difficult to obtain birth histories of good quality. Table I shows that in seven of 13 studies data were collected in whole or in part by asking the mother to recollect quite specific details after the patient had become ill (that is, after the passage of 20 or more years). Clearly neither she nor 0 the person recording the history would have been blind $J$ to the fact that the patient had become mentally ill, and $\mathcal{N}$ it cannot be assumed that this knowledge did not affect $\rightarrow$ the information given or recorded. A more appropriate method is to make use of birth histories recorded N before the onset of illness - that is, obtained through $\mathrm{NJ}^{\mathrm{N}}$ reference to obstetric records. Such records are often unsystematic, and they have been shown to be prone to error. ${ }^{21}$ The weakness of retrospective studies has been discussed by Lewis, who stated that the link between schizophrenia and a history of presumed obstetric 0 complications "hides a wide discrepancy in methodo- 음 logy between studies. Paradoxically, the main $\stackrel{D}{\Omega}$ similarity between the studies is their collective weak- $\mathbb{\mathbb { D }}$ ness: the use of retrospective assessment of obstetric histories even if assessed blindly." ${ }^{22}$

High risk studies ${ }^{23-28}$ may acquire birth histories of a high quality, but accounts of the mental states of the offspring in the period of maximum risk for schizo- $\frac{\bar{\partial}}{7}$ phrenia in adult life are usually not available.

The separate limitations of retrospective and high risk studies can be overcome only by a systematic collection of birth histories of a large cohort in which a 